Article

\title{
Electrochemical Performance of Few-Layer Graphene Nano-Flake Supercapacitors Prepared by the Vacuum Kinetic Spray Method
}

\author{
Mohaned Mohammed Mahmoud Mohammed ${ }^{\mathbb{D}}$ and Doo-Man Chun * (D) \\ School of Mechanical Engineering, University of Ulsan, Ulsan 44610, Korea; hano125@gmail.com \\ * Correspondence: dmchun@ulsan.ac.kr; Tel.: +82-52-259-2706; Fax: +82-52-259-1680
}

Received: 1 July 2018; Accepted: 24 August 2018; Published: 27 August 2018

check for updates

\begin{abstract}
A few-layer graphene nano-flake thin film was prepared by an affordable vacuum kinetic spray method at room temperature and modest low vacuum conditions. In this economical approach, graphite microparticles, a few layers thick, are deposited on a stainless-steel substrate to form few-layer graphene nano-flakes using a nanoparticle deposition system (NPDS). The NPDS allows for a large area deposition at a low cost and can deposit various metal oxides at room temperature and low vacuum conditions. The morphology and structure of the deposited thin films are alterable by changing the scan speed of the deposition. These changes were verified by field emission scanning electron microscopy (FE-SEM), transmission electron microscopy (TEM), $\mathrm{X}$-ray diffraction (XRD), and Raman spectroscopy. The electrochemical performances of the supercapacitors, fabricated using the deposited films and $\mathrm{H}_{3} \mathrm{PO}_{4}-\mathrm{PVA}$ gel electrolytes with different concentrations, were measured using a 2-electrode cell. The electrochemical performance was evaluated by cyclic voltammetry, galvanostatic Charge-discharge, and electrochemical impedance spectroscopy. The proposed affordable fabricated supercapacitors show a high areal capacitance and a small equivalent series resistance.
\end{abstract}

Keywords: nanoparticle deposition system; few-layer graphene nano-flakes; supercapacitor

\section{Introduction}

Supercapacitors, also called ultracapacitors, are promising electrochemical storage devices due to their high-power density, fast charge/discharge rates, and long Charge-discharge cycles [1-4]. Supercapacitors have the potential to supplement or replace the use of batteries for energy storage applications, namely those for wearable and portable electronics, energy storage systems, and electrical and hybrid vehicles [5]. There are two representative types of supercapacitor: (1) the electric double layer capacitor (EDLC); and (2) the pseudocapacitor. EDLCs store energy via ion adsorption/desorption on the electrode surface, exhibit an excellent cycle life and power density, but are restrained by limited adsorption capacity, which adversely impacts their energy density [6]. Carbon materials with a large specific surface area and excellent electrical conductivity, such as active carbon (AC), carbon nanotubes (CNTs), and graphene, have been used for EDLCs. In contrast, pseudocapacitors store energy via fast and reversible surface redox reactions. Typical pseudo-capacitive materials include transition metal oxides/hydroxides and conducting polymers. Pseudocapacitors hold a much higher energy density but have unsatisfactory cycle stability and rate capability, so their power density is generally low [6]. Graphene is a 2D plane of $s p^{2}$ bonded carbon atoms, organized in a honeycomb lattice. There are two reasons why graphene is a particularly suitable material for storage devices. The first reason is that graphene has good electrical conductivity. The electrical conductivity is a result of graphene's unique electronic properties, which include a massless Dirac fermion, 
an ambipolar electric field effect, and an extremely high carrier mobility [7]. These properties arise from the unique electronic band structure of graphene, which is considered a zero-gap conductor [8]. Moreover, due to the high quality of its 2D crystal structure, graphene exhibits fast transport properties, which also results in a low defect density, allowing graphene to behave like a metal with a high constant mobility [9]. The second reason for graphene's suitability for electronic storage is its high surface area. The theoretical calculation of the specific surface area of graphene yields a value of $2630 \mathrm{~m}^{2} / \mathrm{g}$. This is a high specific surface area even compared with the graphite $\left(\sim 10 \mathrm{~m}^{2} / \mathrm{g}\right)$ [1] or CNTs $\left(1315 \mathrm{~m}^{2} / \mathrm{g}\right)$ [10]. These advantages make the graphene and their composites suitable for many applications, such as all-solid-state laser scribed flexible graphene supercapacitor [11], flexible and durable graphene oxide fabricated on cotton textile [12], electrochemically doped graphene [13], graphene/polyaniline nanofiber composite [14], and activation of microwave exfoliated GO (MEGO) and thermally exfoliated GO (TEGO) by $\mathrm{KOH}$ [15] for supercapacitor applications, in addition to cuprous oxide/reduced graphene oxide $\left(\mathrm{CuO}_{2} / \mathrm{rGO}\right)$ nanocomposites for light-controlled conductive switching [16]. Also $\mathrm{CuO}_{2} / \mathrm{rGO}$ exhibits excellent photocatalytic activity [17], and AgInZnS-graphene oxide (GO) nanocomposites can be used as active biomarkers for noninvasive biomedical imaging [18]. Besides that, there are other properties about graphene and their composites such as the excellent mechanical properties and chemical tunability of graphene oxide paper reported by Dikin et al. [19]. However, there is drawback which limits the use of graphene in some applications. The measured values of the graphene specific surface area are much lower than the theoretical value, in the range of $1000-1800 \mathrm{~m}^{2} / \mathrm{g}$ [20]. The lower specific surface area is a result of graphene agglomeration during fabrication of the electrode material, resulting in a loss of surface area [21]. In 2004, Geim and co-workers synthesized the first graphene single layers by mechanical exfoliation using the Scotch tape method [22]. Because of the manual operation, this method has a very small yield, but the graphene obtained by this method was useful for fundamental studies. This method is neither scalable nor can it be adapted for mass production [22,23]. There are two major approaches for producing single layer graphene: the top-down and bottom-up approaches. The purpose of the top-down approach is to reduce the graphite to single or few-layer graphene platelets. Graphite conversion into graphite oxide is a common method in the top-down strategies $[19,24]$. This familiar top-down approach often requires strong reaction conditions, such as high reduction temperatures, while using concentrated sulfuric acid with highly hazardous procedures [25-27]. Moreover, the obtained graphene always suffers from many defects in the structure, rendering its actual electric conductivity poor, thus restricting its applications [28]. The electrochemical exfoliation method has been reported to be promising for the large-scale production of high-quality graphene, however, this approach consumes a large amount of electric energy and the use of high voltages also facilitates the generation of oxygen groups, as well as structural damage of the graphene [25,29]. Also, liquid-phase exfoliation [30] and graphite intercalation compounds (GICs) [31] are all included in the top-down approaches. The advantages of these approaches are that they produce a large area, with a low cost of fabrication. However, many defects are formed through the exfoliation, so it is impossible to get high-quality single-layer graphene [32]. The bottom-up methods require atom by atom growth, which includes growth on $\mathrm{SiC}$, molecular beam epitaxy, chemical vapor deposition, and chemical synthesis [33]. CVD is a method in which graphene is grown directly on a transition metal substrate through saturation of carbon upon exposure to a hydrocarbon gas at a high temperature [34-40]. One of the major advantages of the CVD technique is its high compatibility with the current complementary metal-oxide-semiconductor (CMOS) technology. However, controlling the film thickness is difficult, and the formation of secondary crystals cannot be avoided [41]. Another disadvantage of the CVD method is that it requires expensive substrate materials for graphene growth, which limits the applications for large-scale production. Further, the transfer to another substrate is a complex process. To avoid the disadvantages of the previous strategies, a promising vacuum kinetic spray method was used to deposit few-layer graphene nanoflakes from graphite microparticles, while under room temperature and low vacuum pressure conditions. This vacuum kinetic spray method is known as a nanoparticle deposition system (NPDS). Previously, 
a NPDS was developed to deposit metals and ceramics, such as tin, nickel, $\mathrm{Al}_{2} \mathrm{O}_{3}, \mathrm{TiO}_{2}$, and $\mathrm{WO}_{3}$, at a low temperature. Additionally, few-layer graphene nanoflake layers have been successfully deposited [42-47]. The NPDS uses relatively low pressure compressed air as a carrier gas and a low vacuum pressure (around $0.04 \mathrm{MPa}$ ), for low equipment and processing costs. The impact velocity of the micro-sized graphite particles deposited by NPDS is one of the critical process parameters, and its importance was studied with regard the formation of few-layer graphene flakes on copper foil without binders by Nasim and Chun [46]. Further, these researchers carried out computational fluid dynamics (CFD) simulations to study the relationship between the stand-off distance and the impact velocity. The CFD analysis predicts the critical velocity for fragmentation and interlayer separation of graphite particles for the deposition of a few-layer graphene flake structure on copper, without the presence of unfragmented graphite particles [46]. Another important factor that can affect the deposition of micro-sized graphite particles is the substrate hardness. The substrate-dependent behavior of deposition showed that the degree of fragmentation and interlayer separation increase with an increase in the substrate hardness. By using the NPDS, thick and fragmented graphite particles were deposited on soft substrates, while the deposition on the hard substrates result in a few-layer graphene flake structure [47].

This research introduced a new deposition method for few layered graphene nano-flakes thin film from micro-sized graphite powders without any additives or chemicals, so that this deposition method can be low-cost, and eco-friendly manufacturing technique. The few layered graphene nano-flakes thin film prepared by the NPDS was applied for supercapacitor applications. Herein, the effect of the scan speed on the formation of a few-layer graphene flake structure was studied, and graphite microparticles were deposited on stainless steel using the NPDS for application in relatively low-cost supercapacitors. The surface morphology of the formed films was analyzed by a field-emission scanning electron microscope (FE-SEM), X-ray diffraction (XRD), and Raman spectroscopy. Then, the few-layer graphene nanoflake thin film was used as an electrode of a supercapacitor, with a polyvinyl alcohol with phosphoric acid $\left(\mathrm{PVA}-\mathrm{H}_{3} \mathrm{PO}_{4}\right)$ gel electrolyte serving as a separator and binding material [48]. A polymer gel electrolyte is often used to provide anions and cations, which participate in the surface process, contributing to the electrochemical capacitance [49]. The electrochemical performance was evaluated in a 2-electrode system using cyclic voltammetry (CV), galvanostatic Charge-discharge, and electrochemical impedance spectroscopy (EIS).

\section{Materials and Methods}

\subsection{Materials}

Commercially available graphite powder (MGF 10 995A, Samjung C\&G, Gyeongsan, Korea) with a particle size of $10 \mu \mathrm{m}$ or larger was used in this research for deposition on a stainless steel substrate (SUS304, Nilaco Corporation, Tokyo, Japan), with a thickness of $0.5 \mathrm{~mm}$. Additionally, polyvinyl alcohol (PVA) with an average molecular weight of 88,000 g/mol (\#6716-1405, Daejung Chemicals \& Metals Co., Ltd., Siheung, Korea), and phosphoric acid $\left(\mathrm{H}_{3} \mathrm{PO}_{4}\right)$ with $85 \%$ purity (\#7664-38-2, Daejung Chemicals \& Metals Co., Ltd., Siheung, Korea) were used in the preparation of the supercapacitors.

\subsection{Graphene Electrode Preparation}

The NPDS consists of a compressor, cylindrical powder feeder, nozzle, vacuum chamber, vacuum pump, vibrator, and controller, as shown in Figure 1. The compressor supplies a compressed air of pressure 0.2 MPa to carry the micro-sized graphite powder from the cylindrical powder feeder to the nozzle which is inside the vacuum chamber. In this research, a slit converging-diverging nozzle of dimensions $50 \times 0.2 \mathrm{~mm}^{2}$ was used to accelerate the powder for a large area deposition. A vibrator was used to shake the powder feeder to carry the powder easily to the nozzle. The distance between the nozzle and the stainless-steel substrate was set to be $5 \mathrm{~mm}$. The y-stage is connected to a permanent 
magnet AC (PMAC) motor to control the scan speed of the substrate. In this study the deposition was carried out directly on a stainless-steel substrate by three different scan speeds without any additional chemical or binders, as shown in Table 1.

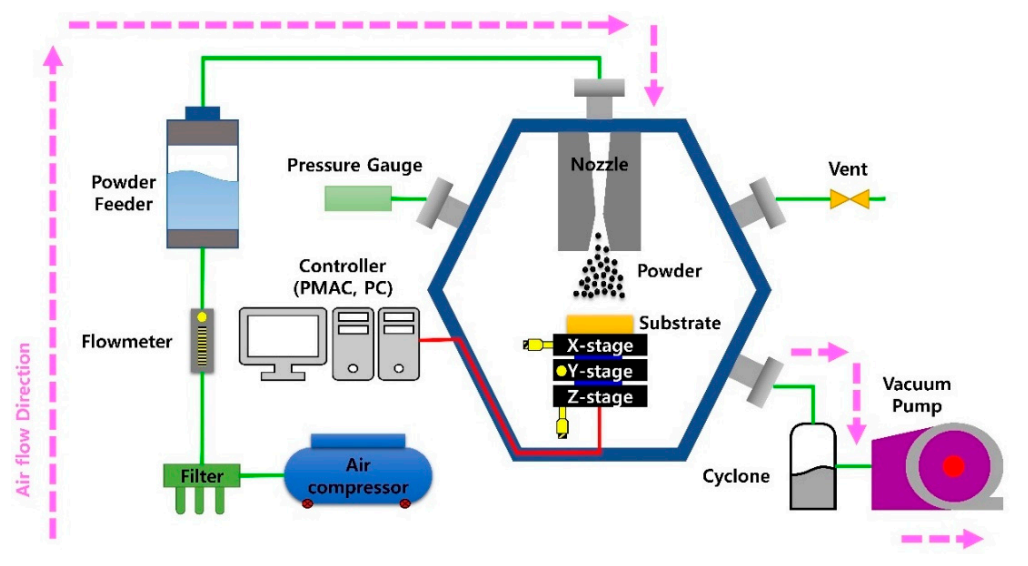

Figure 1. Schematic diagram of the nanoparticle deposition system.

Table 1. Process parameters for graphite deposition on the stainless-steel substrate.

\begin{tabular}{cc}
\hline Parameter & Value \\
\hline Compressor pressure (MPa) & 0.2 \\
Chamber pressure (MPa) & $0.036-0.04$ \\
Scan speed (mm/min) & $0.4,0.8$, and 1.2 \\
Distance between substrate and nozzle $(\mathrm{mm})$ & 5 \\
Deposition shape & $2 \times 5 \mathrm{~cm}^{2}$ \\
Substrate material & Stainless-steel \\
\hline
\end{tabular}

\subsection{Characterization}

The morphology and structure of the deposited film are characterized by field emission scanning electron microscopy (FE-SEM) (JSM-6500F, JEOL, Tokyo, Japan). The crystalline structures of the as-purchased graphite powder and the deposited film on a stainless-steel substrate were examined by XRD (Ultra 4, Rigaku, Tokyo, Japan). Raman Spectra were recorded using Raman spectroscopy (Alpha 300R, WITec GmbH, Ulm, Germany) with a $532 \mathrm{~nm}$ wavelength laser operating at $1 \mathrm{~mW}$ as an excitation source. Focused ion beam (FIB) (Helios NanoLab 450, FEI, Eindhoven, The Netherlands) milling was carried out to prepare the high-resolution transmission electron microscopy (HR-TEM) sample. A FIB lift-out TEM grid (FIB lift-out Cu TEM grid with 3 posts, Omniprobe, Inc., Dallas, TX, USA) was used to hold the milled HR-TEM sample. Finally, the sample prepared by the FIB was used for HR-TEM (JEM-2100F, JEOL, Tokyo, Japan).

\subsection{Preparation of the Polymer Gel Electrolyte}

The polymer gel electrolyte was prepared as follows. $1 \mathrm{~g}$ of PVA was stirred in $10 \mathrm{~mL}$ of deionized water at $80{ }^{\circ} \mathrm{C}$ for 2 hours until completely dissolved. After cooling, $0.03 \mathrm{~mol}$ (2.94 gm) of $\mathrm{H}_{3} \mathrm{PO}_{4}$ were added to the PVA and stirring was continued until the solution became a viscous gel. The sane procedure was followed to prepare 0.06 and 0.09 mol of $\mathrm{H}_{3} \mathrm{PO}_{4}-\mathrm{PVA}$ gel electrolyte by adding 5.88 and $8.82 \mathrm{gm}$ of $\mathrm{H}_{3} \mathrm{PO}_{4}$ to the $1 \mathrm{gm}$ of PVA respectively.

\subsection{Assembly of Supercapacitor Device}

The graphene thin film was deposited on the stainless-steel with area $10 \times 10 \mathrm{~mm}^{2}$. To fabricate a supercapacitor, the deposited area was dipped on the $\mathrm{H}_{3} \mathrm{PO}_{4}-\mathrm{PVA}$ gel electrolyte for a minute, the electrolyte on the electrode was left in air overnight to dry. After this, the two identical electrodes 
with the dried electrolytes were sandwiched together by applying a $1 \mathrm{~kg}$ weight, resting on the top, to ensure a full contact. The fabrication process is shown in Figure 2.

(a)

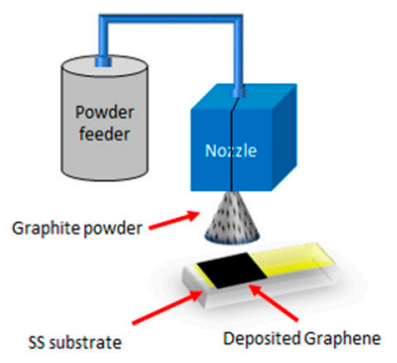

(c)

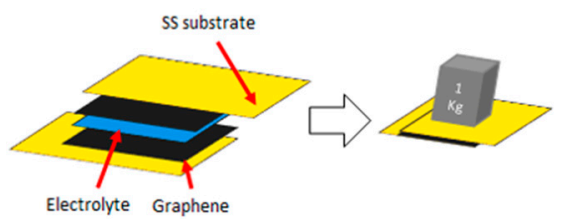



(d)

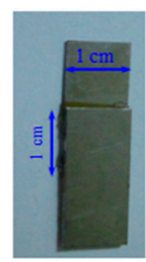

Figure 2. (a) Thin film deposition by nanoparticle deposition system (NPDS); (b) dipping deposited electrode into the gel electrolyte; (c) sandwiching the two identical electrodes and applying mechanical force; and (d) actual image of the fabricated supercapacitor.

\subsection{Electrochemical Measurements}

The electrochemical properties were measured using a 2-electrode cell. The electrochemical performance was measured using a CorrTest electrochemical workstation (C350, Wuhan Corrtest Instruments Corp. Ltd., Wuhan, China), using cyclic voltammetry, galvanostatic Charge-discharge, and electrochemical impedance spectroscopy. The cyclic voltammetry measurement was scanned between 0 and $1 \mathrm{~V}$ with different scan rates between 2 and $100 \mathrm{mV} / \mathrm{s}$. The galvanostatic Charge-discharge tests were performed at different current densities. Impedance data was collected, ranging from $1 \mathrm{MHz}$ to $1 \mathrm{~Hz}$, with an open circuit potential (OCP), with an AC signal $10 \mathrm{mV}$ in amplitude.

\section{Results and Discussion}

\subsection{Morphology Properties}

After deposition, the masses per unit area and thicknesses of the deposited films with different scan speeds were calculated. The mass per unit area of the deposited films decreased as the scan speed increased from 0.4 to 0.8 and $1.2 \mathrm{~mm} / \mathrm{min}$. The thickness of each deposited film was measured by confocal microscopy, showing that as the scan speed changed from 0.4 to $1.2 \mathrm{~mm} / \mathrm{min}$ the thickness decreased. The values of mass per unit area and the corresponding thicknesses are shown in Table 2 and Figure 3.

Table 2. Thickness and mass values of the deposited films with different scan speeds.

\begin{tabular}{ccc}
\hline Scan Speed $(\mathbf{m m} / \mathbf{m i n})$ & Thickness $(\boldsymbol{\mu m})$ & Mass $\left(\mathbf{m g} / \mathrm{cm}^{2}\right)$ \\
\hline 0.4 & 2.53 & 0.3 \\
0.8 & 1.54 & 0.17 \\
1.2 & 0.85 & 0.101 \\
\hline
\end{tabular}




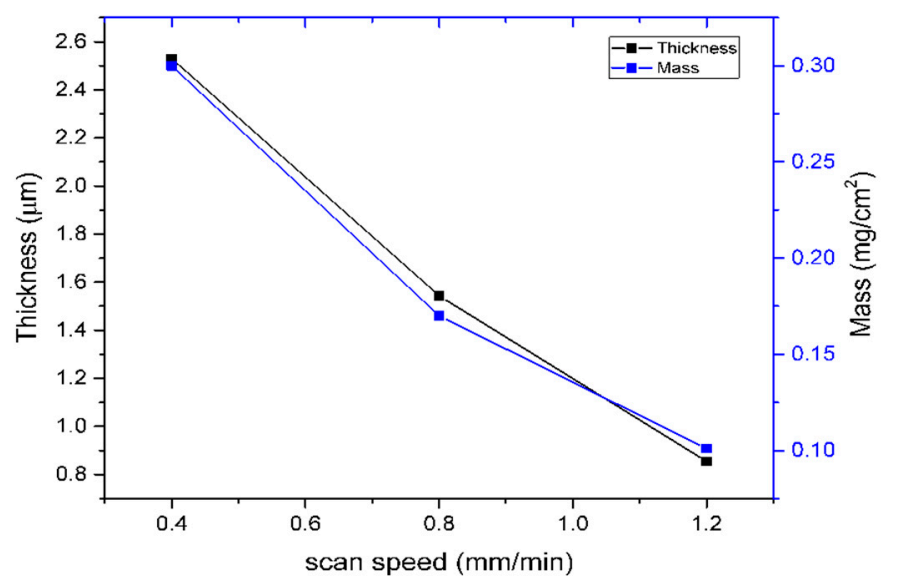

Figure 3. Mass per unit area verses the thickness of the deposited films with scan speeds $0.4,0.8$ and $1.2 \mathrm{~mm} / \mathrm{min}$.

The surface morphology of the original graphite powder and the deposited thin film, on a stainless-steel substrate, was observed with an FE-SEM. Figure 4a is the FE-SEM image of the original graphite powder, showing that the sizes of the original powder particles are around $6 \mu \mathrm{m}$ and the shapes are irregular. Figure $4 \mathrm{~b}-\mathrm{g}$ shows the surface morphology of the deposited films on stainless steel, by comparing Figure 4 a with Figure 4 b,c, we can see that most of the graphite powder fragmented to small particles; some of these particles are still in microscale graphite form, but most of the other particles are converted to very small flakes. As seen in Figure $4 \mathrm{~d}-\mathrm{g}$, as the scan speed increased, the relative proportion of the microscale graphite particles on the deposited films become smaller relative to the slow scan speed case $(0.4 \mathrm{~mm} / \mathrm{min})$. For $1.2 \mathrm{~mm} / \mathrm{min}$ scan speed of deposition, the sizes of most of the fragmented particles ranged from about 100-180 nm, however, there were some fragmented particles with much smaller size. In Figure $4 \mathrm{c}, \mathrm{e}, \mathrm{g}$, red arrows indicate some of the graphene nano-flakes. The thin layers of graphite were separated during the NPDS deposition due to their high impact velocity. The orientation of the particle may be random during deposition, and particles with different orientations collided with the substrate. Due to the high-velocity impact, interlayer sliding and interlayer separation occurred and very thin structures were deposited on the stainless-steel substrate. In addition, large particles broke into small pieces to make nano-sized, thin structures.

Figure 5 shows the TEM image of the deposited film with a scan speed of $1.2 \mathrm{~mm} / \mathrm{min}$. The HR-TEM image shown in Figure 5a indicates the crystalline structure of randomly oriented graphene nano-flakes with some areas of amorphous structure. The Fast Fourier transformer (FFT) of the HR-TEM image in Figure $5 \mathrm{~b}$ shows a polycrystalline structure which has arisen from the short-range randomly oriented graphene flakes. The obtained histogram plot is shown in Figure $5 \mathrm{c}$ at the surrounded position by the yellow rectangle in Figure 5a indicates an in-plane lattice spacing of $0.26 \mathrm{~nm}$ corresponding to the graphene lattice spacing [50,51]. Other crystalline areas showed the same lattice spacing of $0.26 \mathrm{~nm}$, as all positions were measured using the histogram plot. This suggests that all crystalline areas are graphene structured. In Figure 5d, the highly magnified image of the surrounded position by the yellow rectangle in Figure 5a shows a triangular sublattice pattern of carbon atoms instead of a hexagonal pattern. This triangular pattern may come from few-layer graphene flake structures $[52,53]$. The corresponding FFT clearly shows a hexagonal pattern of the graphene structure corresponding to the (100) plane. 

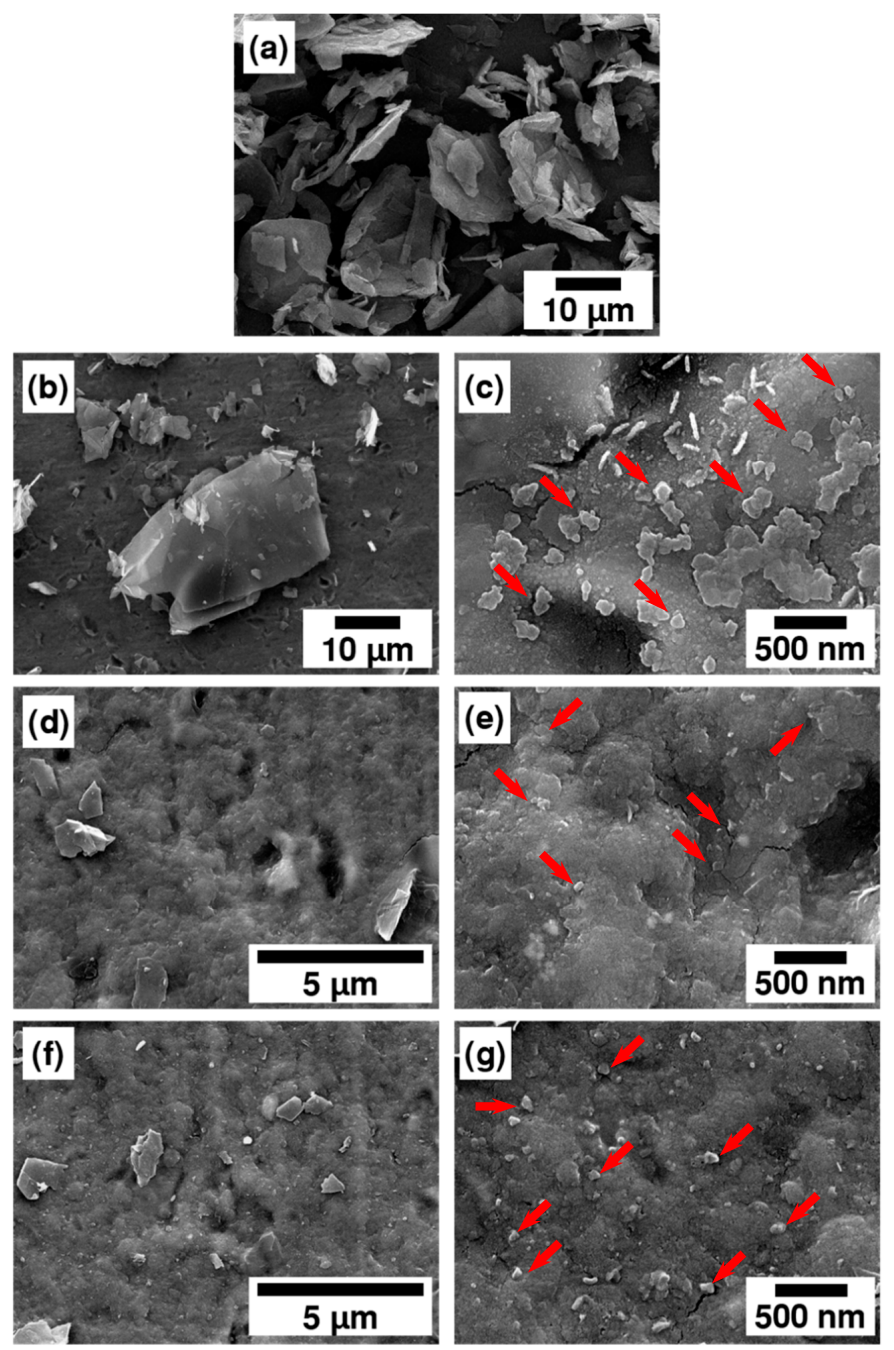

Figure 4. Field emission scanning electron microscopy (FE-SEM) of (a) graphite powder, deposited film at scan speeds of $(\mathbf{b}, \mathbf{c}) 0.4,(\mathbf{d}, \mathbf{e}) 0.8$, and $(\mathbf{f}, \mathbf{g}) 1.2 \mathrm{~mm} / \mathrm{min}$, respectively.
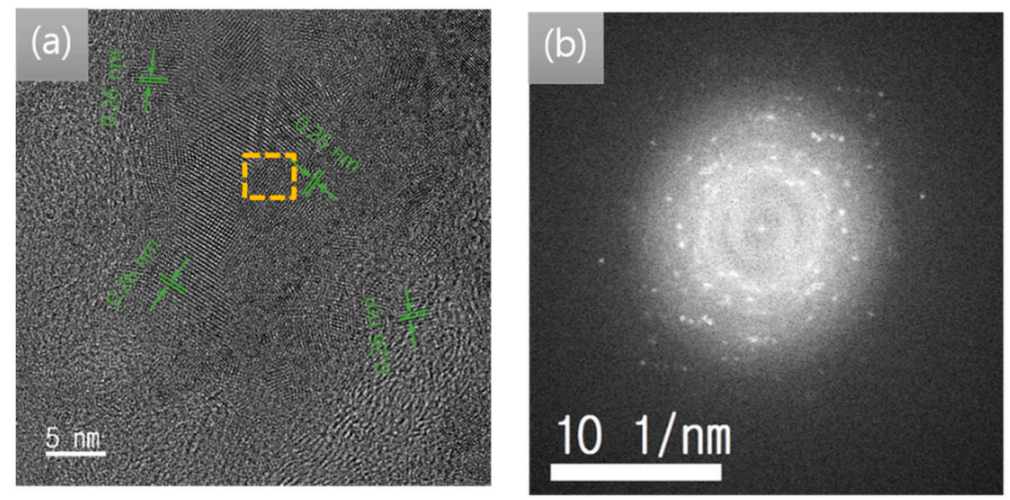

Figure 5. Cont. 

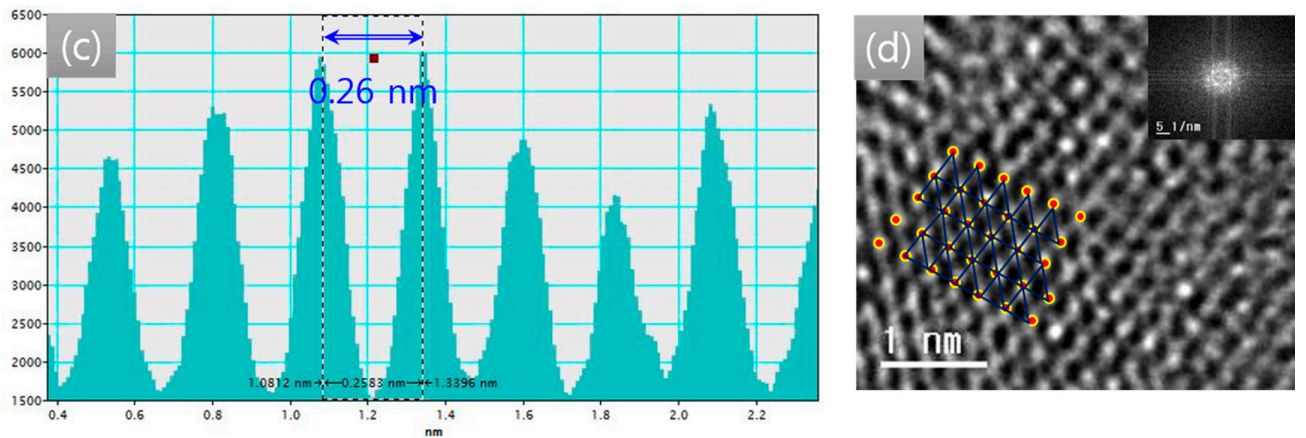

Figure 5. (a) High-resolution transmission electron micropscopy (HR-TEM) image of the deposited film with scan speed $1.2 \mathrm{~mm} / \mathrm{min}$; (b) Fast Fourier transform (FFT) of image (a); (c) Histogram plot of the area surrounded by the yellow rectangular in (a); (d) Magnified HR-TEM of the area surrounded by the yellow rectangular in (a) (in the top right, FFT of image (d) was inserted).

\subsection{X-ray Diffraction Analysis}

The structural properties of original graphite powder, and the deposited films with different scan speeds $(0.4,0.8$, and $1.2 \mathrm{~mm} / \mathrm{min})$ and stainless-steel substrate were characterized using XRD analysis. Figure 6 shows the XRD spectrum of the original graphite powder, the sharp and high amplitude peak (002) at $2 \theta=26.5^{\circ}$, which is the strongest peak obtained in the diffraction pattern in the direction perpendicular (c-axis) to the graphite hexagonal plates, indicates a highly organized layered structure with an interplanar spacing of $0.365 \mathrm{~nm}$. The XRD spectrum of the deposited films shows peaks $\gamma(111), \gamma(200)$, and $\alpha(211)$ at $43.6^{\circ}, 50.5^{\circ}$, and $82^{\circ}$ corresponding to the stainless steel substrate. In the of $0.4 \mathrm{~mm} / \mathrm{min}$ case, there is (002) graphite peak at $26.3^{\circ}$. This peak disappeared when the scan speed was increased to 0.8 and $1.2 \mathrm{~mm} / \mathrm{min}$, which means that the graphene/graphite structure in case of $0.4 \mathrm{~mm} / \mathrm{min}$ scan speed of deposition transformed to graphene structure as the scan speed increased. Also, the deposited films show a broad carbon (002) peak between $15^{\circ}$ and $25^{\circ}$, the broadness of the (002) peak and the shift to a smaller angle indicates a decrease in the particle size due to defragmentation of graphite microparticles to graphene nano-flakes and an increase in the interplanar spacing.

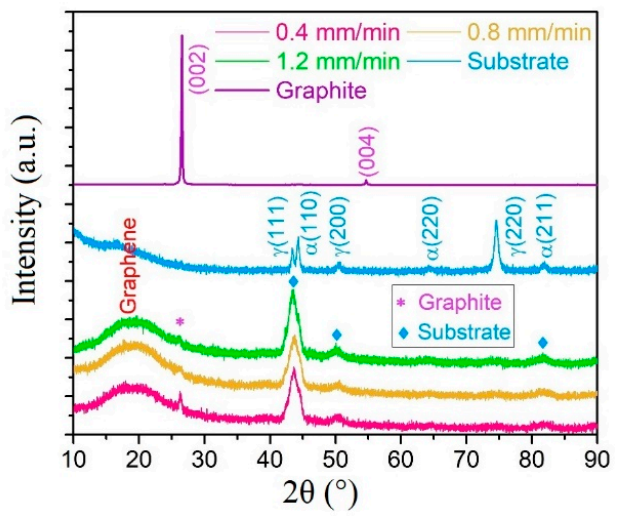

Figure 6. X-ray diffraction (XRD) of the graphite powder, SUS304 substrate, and deposited films at different scan speeds.

\subsection{Raman Spectroscopy}

The Raman spectroscopy results of the original graphite powder and deposited films are shown in Figure 7. It is obvious that the graphite powder has mainly three bands, D, G, and 2D, at 1352.4, 1582.1, and $2720.77 \mathrm{~cm}^{-1}$, respectively. The $\mathrm{G}$ peak is due to the doubly degenerate zone center $E_{2 \mathrm{~g}}$ mode [54]. 
The $G$ band has the most intense peak and the D band has negligible intensity. The negligible intensity of the $\mathrm{D}$ band suggests a crystalline structure with almost no disorder. The 2D band for graphite consists of two bands $2 \mathrm{D}_{1}$ and $2 \mathrm{D}_{2}$, as shown in the enlarged view of the $2 \mathrm{D}$ peak, the double band structure of the 2D peak was explained by other researchers [55-60]. For all of the deposited films under all scan speeds $(0.4,0.8$ and $1.2 \mathrm{~mm} / \mathrm{min})$, the deposited film on stainless steel substrate showed two different behaviors. During measurement, the laser beam was focused in two different positions for a more accurate measurement. When the laser beam was focused on a larger size, fewer fragmented particles were produced, as shown in Figure 7a. In this case, the D peak was located at $1352.4 \mathrm{~cm}^{-1}$ for all deposited films, the $G$ peak positions, for the slower to faster scan speeds, were at 1586, 1592 and $1596 \mathrm{~cm}^{-1}$. We can observe that the ratio of $I_{\mathrm{D}} / I_{\mathrm{G}}$, as shown in Table 3, becomes higher when the scan speed of deposition increases, which confirms that the amount of graphite structure on the deposited films decreases as the scan speed of the deposition is increases. 2D peaks appear around 2718, 2708 and $2699 \mathrm{~cm}^{-1}$, respectively for the different scan speeds of deposition. The shift of the $G$ band to a higher energy compared to the graphite powder, the sharpness of 2D peak, and the shift in the 2D band to a lower energy, all indicate that while increasing the scan speed of deposition, more of micro-sized graphite particles gradually transform from graphite to a few-layer graphene structure.

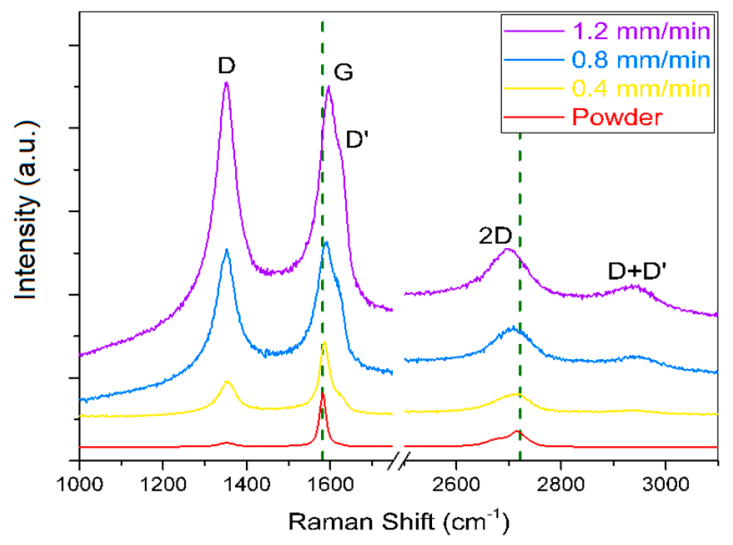

(a)

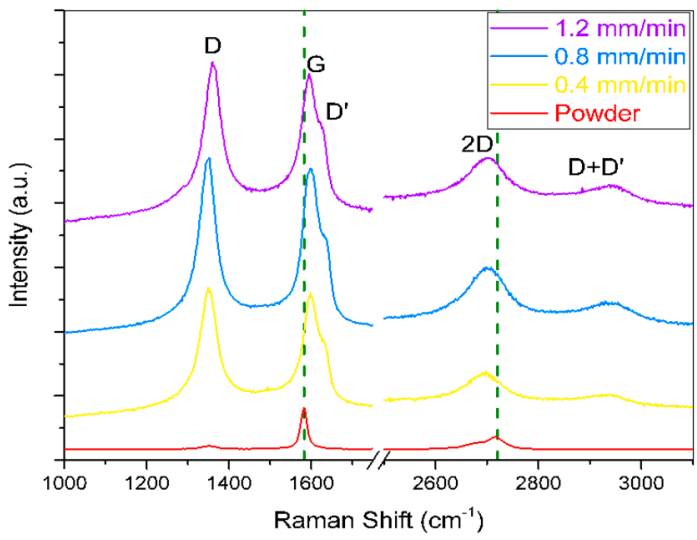

(b)

Figure 7. Raman spectroscopy of (a) the graphite powder and deposited films at different scan speeds on larger size particles with less fragmentation and (b) graphite powder and deposited films at different scan speeds on the more fragmented particles.

When the laser beam was focused on the fragmented particles, the Raman spectrum of the deposited thin films under all scan speeds $(0.4,0.8$ and $1.2 \mathrm{~mm} / \mathrm{min})$ has a different interesting behavior; as seen in Figure $7 \mathrm{~b}$, the intensity of D band peaks at 1352.4, 1352.4, and $1350.8 \mathrm{~cm}^{-1}$ respectively, which represents the disorder was higher than the $\mathrm{G}$ band appears around 1598.5, 1597, and $1595 \mathrm{~cm}^{-1}$, respectively, for the different scan speeds of deposition, which means that the $I_{\mathrm{D}} / I_{\mathrm{G}}$ for the deposited film is much higher than that of the graphite powder. This increase in $I_{\mathrm{D}} / I_{\mathrm{G}}$ can be described because of the fragmentation of the micro-sized graphite particles to graphene nano-flakes, which increase the edge defects and disorder of the graphene. The $G$ band is shifted to a higher energy compared to the graphite powder, as shown in Figure $7 \mathrm{~b}$. The $\mathrm{G}$ band has a shoulder at $1654 \mathrm{~cm}^{-1}$ ( $\mathrm{D}^{\prime}$ band). Also, the 2D band, which appears around $2698 \mathrm{~cm}^{-1}$, for all deposited films, is shifted to lower energy compared to the graphite powder. The 2D band of the deposited film is sharper than that of the original powder. Moreover, the shift in the 2D band indicates that the thickness of the deposited film is decreases after deposition of the original graphite powder on stainless steel using the NPDS. Based on the shifts in the G and 2D peaks, we concluded that the layers of micron-sized graphite powder were separated due to the high impact velocity during deposition, and that few-layer graphene structures have formed on the stainless steel [55,61]. Furthermore, the strong and sharp D 
band peak and $\mathrm{D}^{\prime}$ band peak suggest a nanocrystalline structure, as well as the presence of graphene edges and defects [62-64]. These graphene edges may appear due to fragmented graphene flake structures. Furthermore, defects may have occurred during the high impact velocity deposition, or by interactions between the stainless steel and graphene, which may have produced vacancies, dislocation, and/or dangling bonds [65]. The positions of the $D, G$, and 2D peaks for the graphite powder and deposited films are shown in Table 3.

Table 3. $\mathrm{D}, \mathrm{G}$, and $2 \mathrm{D}$ peaks and $I_{\mathrm{D}} / I_{\mathrm{G}}$ for the graphite powder and deposited films.

\begin{tabular}{|c|c|c|c|c|c|c|c|c|}
\hline \multirow[b]{2}{*}{ Sample } & \multicolumn{4}{|c|}{ Large Size \& Less Fragmented Particles } & \multicolumn{4}{|c|}{ Fragmented Particles } \\
\hline & $\begin{array}{l}\text { D Peak } \\
\left(\mathrm{cm}^{-1}\right)\end{array}$ & $\begin{array}{l}\text { G Peak } \\
\left(\mathrm{cm}^{-1}\right)\end{array}$ & $\begin{array}{c}\text { 2D Peak } \\
\left(\mathrm{cm}^{-1}\right)\end{array}$ & $I_{\mathrm{D}} / I_{\mathrm{G}}$ & $\begin{array}{l}\text { D Peak } \\
\left(\mathrm{cm}^{-1}\right)\end{array}$ & $\begin{array}{l}\text { G Peak } \\
\left(\mathrm{cm}^{-1}\right)\end{array}$ & $\begin{array}{c}\text { 2D Peak } \\
\left(\mathrm{cm}^{-1}\right)\end{array}$ & $I_{\mathrm{D}} / I_{\mathrm{G}}$ \\
\hline Powder & 1352.4 & 1582.1 & 2720.8 & 0.269 & 1352.4 & 1582.1 & 2720.8 & 0.269 \\
\hline $0.4 \mathrm{~mm} / \mathrm{min}$ & 1352.4 & 1586 & 2718 & 0.647 & 1352.4 & 1598.5 & 2698 & 1.054 \\
\hline $0.8 \mathrm{~mm} / \mathrm{min}$ & 1352.4 & 1592 & 2708 & 0.970 & 1352.4 & 1597 & 2698 & 1.064 \\
\hline $1.2 \mathrm{~mm} / \mathrm{min}$ & 1352.4 & 1596 & 2699 & 1.009 & 1350.8 & 1595 & 2698 & 1.069 \\
\hline
\end{tabular}

\subsection{Electrochemical Properties}

The electrochemical performance of graphene supercapacitors, fabricated from the deposited films

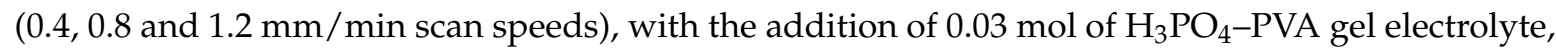
were investigated as part of a 2-electrode system. Figure $8 \mathrm{a}-\mathrm{c}$ shows the cyclic voltammetry curves measured at the scan rates $2-100 \mathrm{mV} / \mathrm{s}$ and potential window $0-1 \mathrm{~V}$. The areal capacitance calculated from the $\mathrm{CV}$ curves using the formula

$$
C_{a}=\frac{\int I d V}{s A \Delta V}
$$

where $I$ is the response current, $\mathrm{s}$ is the scan rate, $\Delta V$ is the potential window and $A$ is the area of graphene electrode in contact with the electrolyte. The $\mathrm{CV}$ curves of graphene supercapacitor are symmetrical and have a near-rectangular shape over the $1 \mathrm{~V}$ potential window, which is typical of an ideal capacitor. The value of areal capacitance was increased from $0.68 \mathrm{mF} / \mathrm{cm}^{2}$ at $2 \mathrm{mV} / \mathrm{s}$ for $0.4 \mathrm{~mm} / \mathrm{min}$ scan speed to $1.28 \mathrm{mF} / \mathrm{cm}^{2}$ at $2 \mathrm{mV} / \mathrm{s}$ for $1.2 \mathrm{~mm} / \mathrm{min}$ scan speed, as shown in Figure $8 \mathrm{~d}$, two factors explain this improvement of the capacitance: In case of a fast scan speed, after the graphite particles were accelerated to supersonic speeds through the converging-diverging nozzle, the graphite particles impact with the stainless steel substrate, which has relatively high hardness, so a thin layer of graphene will be formed on the substrate, the deposition quickly will cover another location until it covers the required area of substrate. On the other hand, for the slow scan speed, after the acceleration of graphite powder, the impact takes place at first between the powder and stainless-steel substrate. As in the case of a fast scan speed, a thin graphene layer will form over the substrate, but due to the slow scan speed the impact will happen between the graphite powder and the deposited film, which has a lower hardness than the stainless steel. Therefore, the amount of fragmentation of graphite powders becomes lower than that which occurs with a fast deposition scan speed. This is clear from the (002) graphite peak intensity found in the XRD analysis, which decreased as the scan speed increased. Also, this is clear from the Raman spectroscopy, as previously mentioned. In summary, a slow scan speed shows graphene/graphite structure that has a smaller surface area and lower conductivity than graphene structure in the fast scan speed. As such, the improvement of the capacitance can be explained as a result of two reasons. The first reason is that the graphite structure of the deposited film forms more readily with a slow scan speed deposition, such that the specific surface area becomes higher than in the case of a fast scan speed deposition and allow more charge transfer on the surface of the electrode [66]. The second reason is that the number of graphene layers is decreases with an increase in the scan speed, since the value of $I_{\mathrm{D}} / I_{\mathrm{G}}$ for a fast scan speed is larger than that of low scan speed and the decreased number of graphene layers can improve the charge transfer inside the electrode material $[67,68]$. 

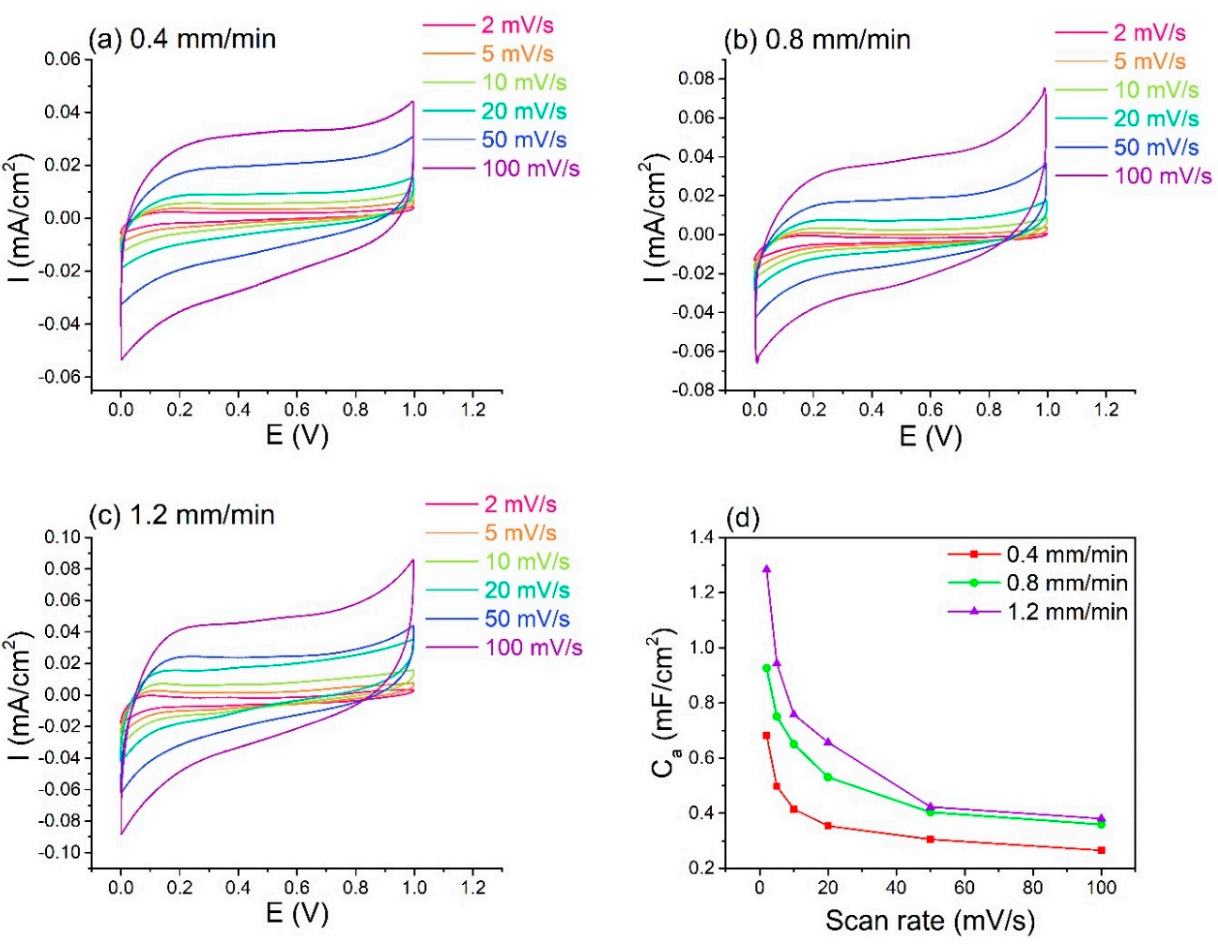

Figure 8. (a-c) Cyclic voltammetry (CV) curves of 0.03 mol of $\mathrm{H}_{3} \mathrm{PO}_{4}$ gel electrolyte with different scan speeds; (d) Calculated specific areal capacitance from CV curves.

In Figure 9, the cyclic voltammetry was measured again for the deposited films using 0.06 and $0.09 \mathrm{~mol} \mathrm{H}_{3} \mathrm{PO}_{4}$-PVA gel electrolytes. Both electrolytes have quasi-rectangular $\mathrm{CV}$ curves and the areal capacitance was $1.28 \mathrm{mF} / \mathrm{cm}^{2}$ at $2 \mathrm{mV} / \mathrm{s}$ for the case of a $1.2 \mathrm{~mm} / \mathrm{min}$ scan speed with $0.03 \mathrm{~mol}$ of $\mathrm{H}_{3} \mathrm{PO}_{4}-\mathrm{PVA}$ gel electrolyte. This value became $1.47 \mathrm{mF} / \mathrm{cm}^{2}$ at $2 \mathrm{mV} / \mathrm{s}$ when the concentration of $\mathrm{H}_{3} \mathrm{PO}_{4}$ was increased to $0.06 \mathrm{~mol}$ and increased to $1.67 \mathrm{mF} / \mathrm{cm}^{2}$ at $2 \mathrm{mV} / \mathrm{s}$ for the case of $0.09 \mathrm{~mol}$ of $\mathrm{H}_{3} \mathrm{PO}_{4}$. It appears that the areal capacitance increases gradually while increasing the concentration in the range of $0.03-0.09$ mol. These results confirm the assumption that the high ion concentration cloud improves the areal capacitance value, which also agrees with previous research $[69,70]$. The capacitance of graphene electrode is mainly due to the diffusion of ions from the electrolyte to the surface of the electrode, and the rate of the whole electrode reaction will be enhanced if the diffusion resistance is decreased. In this sense, a high concentration of $\mathrm{H}_{3} \mathrm{PO}_{4}-\mathrm{PVA}$ gel electrolyte with a high ionic conductivity will provide a low diffusion resistance. The diffusion resistance ( $R_{\mathrm{ct}}$ : charge transfer resistance) can be seen in the Nyquist plot. Previous studies have also found that there is a relationship between the specific capacitance of the activated carbons and the electrolyte conductivity, i.e., the specific capacitance increased with increasing electrolyte conductivity [71]. For $0.06 \mathrm{~mol}$ of $\mathrm{H}_{3} \mathrm{PO}_{4}$, the oxidation and reduction peak at $\sim 0.4$ and $0.25 \mathrm{~V}$ in Figure 9a are corresponding to the pseudocapacitance after phosphorus-doping in graphene layers [72-74]. The doping of phosphorus may be happened during the electrochemical measurement due to the porous structure of the carbon atoms. The existence of phosphorus atoms introduces a positive charge on the neighboring carbon atoms and creates centers for oxygen reduction reaction [73]. Also, in case of $0.09 \mathrm{~mol}_{\text {of }} \mathrm{H}_{3} \mathrm{PO}_{4}$, there is a small oxidation and reduction humps at the same potentials due to the same reason. The samples with relatively low concentration of $\mathrm{H}_{3} \mathrm{PO}_{4}$ $(0.03 \mathrm{~mol})$ did not show the oxidation and reduction peak in the $\mathrm{CV}$ curves. Therefore, a relatively high concentration of $\mathrm{H}_{3} \mathrm{PO}_{4}$ may easily create the doping of phosphorus during the electrochemical measurement. The reactions related to pseudocapacitance can be considered as follows $[75,76]$ :

$$
\zeta \mathrm{C}-\mathrm{OH} \rightleftharpoons \mathrm{C}=\mathrm{O}+\mathrm{H}^{+}+\mathrm{e}^{-}
$$



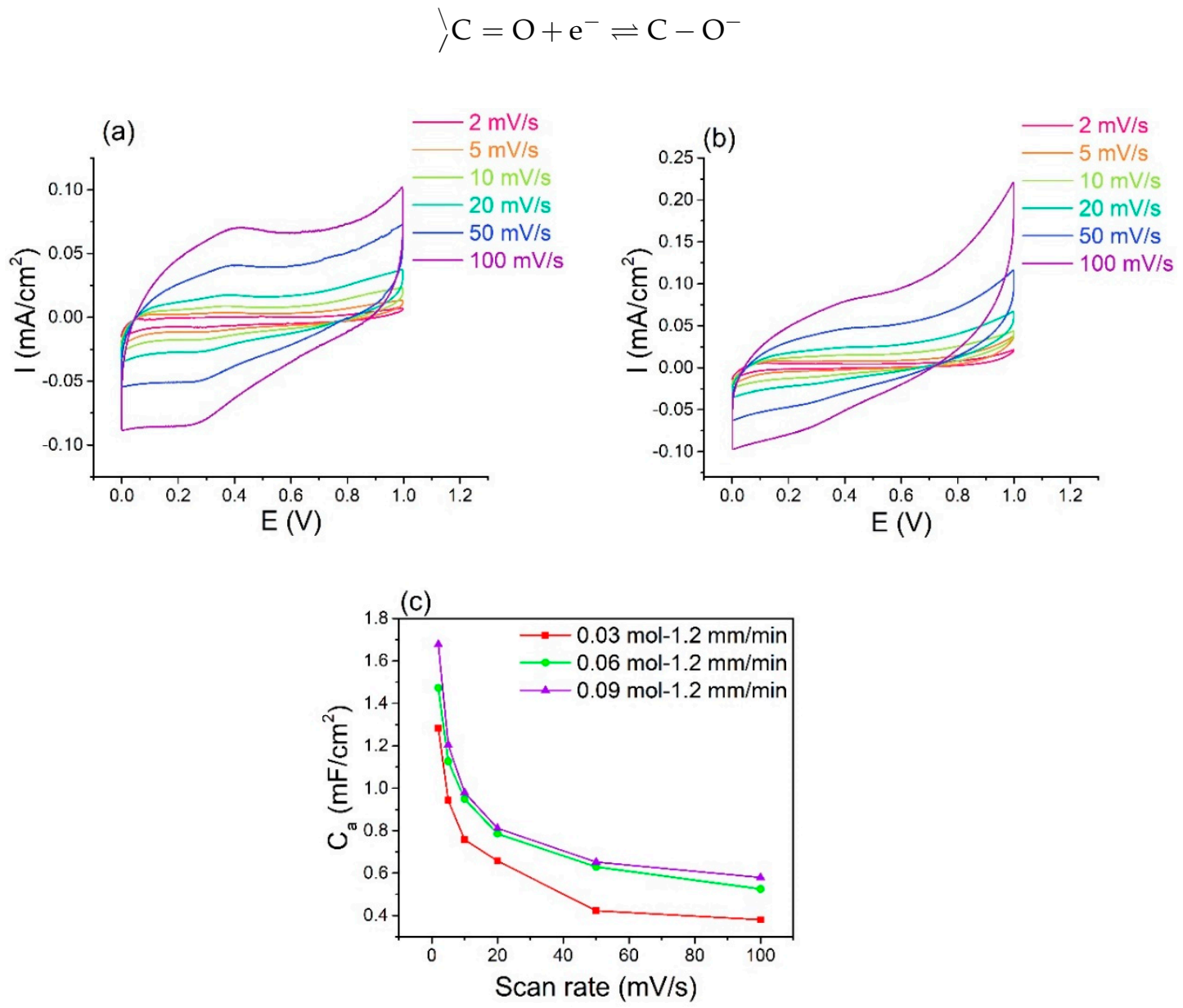

Figure 9. $\mathrm{CV}$ curves of (a) 0.06 and (b) $0.09 \mathrm{~mol}$ of $\mathrm{H}_{3} \mathrm{PO}_{4}$ gel electrolyte with a $1.2 \mathrm{~mm} / \mathrm{min}$ scan speed electrode; (c) The calculated areal capacitance for 0.06 and 0.09 mol of $\mathrm{H}_{3} \mathrm{PO}_{4}$ gel electrolyte with a $1.2 \mathrm{~mm} / \mathrm{min}$ scan speed electrode.

The redox reaction attributed to the reversible quinone/hydroquinone pair.

The galvanostatic Charge-discharge curves for the supercapacitors assembled from the deposited films, with different scan speeds $(0.4,0.8$ and $1.2 \mathrm{~mm} / \mathrm{min})$, in Figure 10a-c, and 0.03, 0.06 and $0.09 \mathrm{~mol}$ of $\mathrm{H}_{3} \mathrm{PO}_{4}-\mathrm{PVA}$ gel electrolyte, in Figure 11, were investigated at current densities $0.01-0.1 \mathrm{~mA}$. The areal capacitance was calculated from the $\mathrm{CV}$ curves using the formula

$$
C_{a}=\frac{I}{\frac{d V}{d t}}
$$

where $I$ is the current density and $d V / d t$ is the slope of discharge curve after the $I R$ drop, where $R$ is the internal resistance of the supercapacitor. Figure 10a-c shows the galvanostatic Charge-discharge curves for all supercapacitors, linear charge and discharge curves with a neglectable $I R$ drop, indicating that the electrodes have a lower internal resistance, which leads to better EDL performance. The areal capacitance calculated from discharge curves is shown in Figure 10d. The results are in agreement with cyclic voltammetry, where the areal capacitance is increased by controlling the thickness of the deposited films by the scan speed of the deposition, for 0.03 mol of $\mathrm{H}_{3} \mathrm{PO}_{4}-\mathrm{PVA}$ gel electrolyte the areal capacitance was $0.39 \mathrm{mF} / \mathrm{cm}^{2}$ for the case of a $0.4 \mathrm{~mm} / \mathrm{min}$ scan speed. This value increased to $1.07 \mathrm{mF} / \mathrm{cm}^{2}$ when the thickness of the deposited film decreased by increasing the scan speed to $1.2 \mathrm{~mm} / \mathrm{min}$. Also increasing the concentration of $\mathrm{H}_{3} \mathrm{PO}_{4}$ in the gel electrolyte from 0.03 to $0.09 \mathrm{~mol}$ improves the areal capacitance, which increased to $1.2 \mathrm{mF} / \mathrm{cm}^{2}$ for the case of a $1.2 \mathrm{~mm} / \mathrm{min}$ scan speed 
with 0.09 mol of $\mathrm{H}_{3} \mathrm{PO}_{4}-\mathrm{PVA}$ gel electrolyte. All areal capacitances are calculated from galvanostatic Charge-discharge at $0.01 \mathrm{~mA}$ of current.
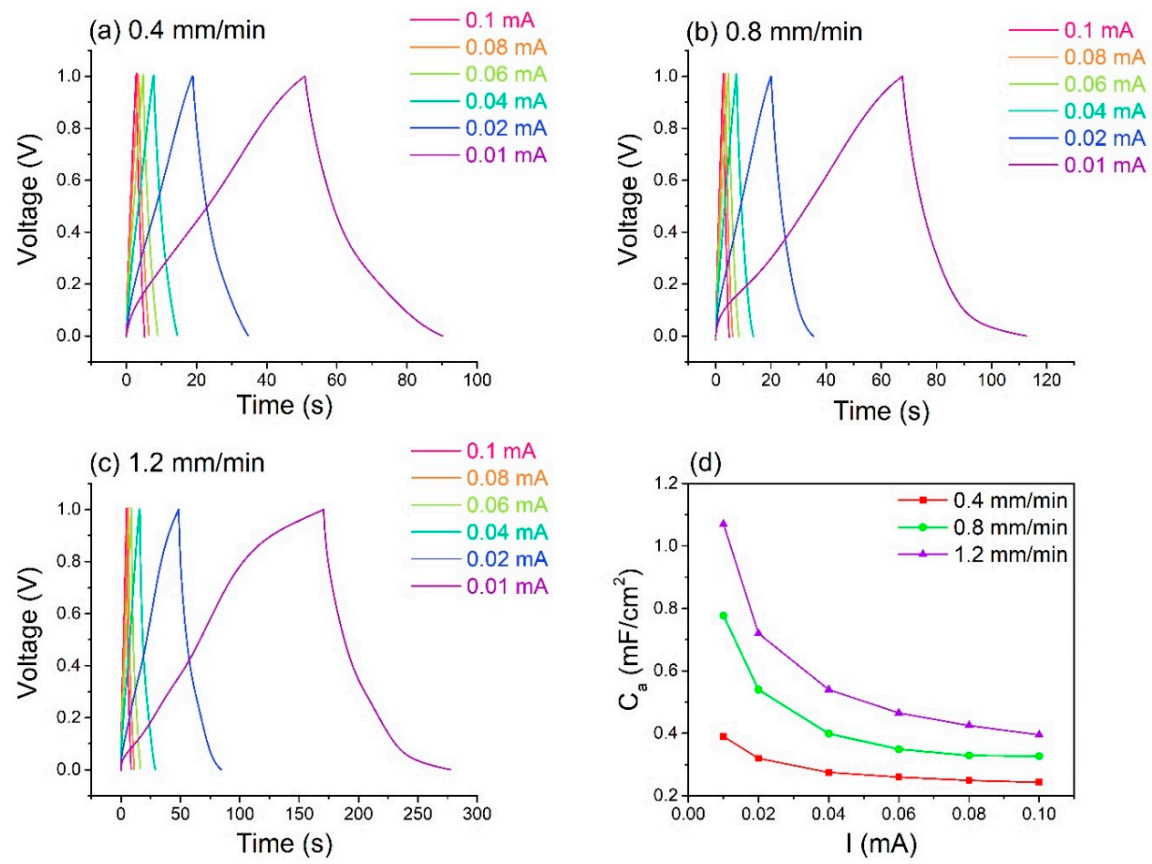

Figure 10. (a-c) Galvanostatic Charge-discharge curves of $0.03 \mathrm{~mol}$ of $\mathrm{H}_{3} \mathrm{PO}_{4}$ gel electrolyte with different scan speeds; (d) Calculated specific areal capacitance from Charge-discharge curves.

Other researchers previously have reported areal capacitances of 3.7 and $2.13 \mathrm{mF} / \mathrm{cm}^{2}$ by CVD [48] and CVD with chemical treatment [77]. The supercapacitor prepared by NPDS shows an areal capacitance $1.67 \mathrm{mF} / \mathrm{cm}^{2}$; even though the value is smaller than those found by other researchers, but the fabrication process is much easier, cheaper, and it can be easily applied in industry because it allows a large area deposition in a small amount of time. The supercapacitor prepared by NPDS is superior to those produced by many other, techniques such as LBL $\left(394 \mu \mathrm{F} / \mathrm{cm}^{2}\right)$ [78], electrochemical reduction of GO $\left(487 \mu \mathrm{F} / \mathrm{cm}^{2}\right)$ [45], vertically oriented graphene $\left(0.087 \mathrm{mF} / \mathrm{cm}^{2}\right)$ [79], graphene-CNT carpets $\left(0.23 \mathrm{mF} / \mathrm{cm}^{2}\right)[45,80]$, and graphene-PEDOT: PSS hybrid films $\left(0.179 \mathrm{mF} / \mathrm{cm}^{2}\right)[45,81]$.

Electrochemical impedance spectroscopy (EIS) measurements were carried out to understand the electrochemical details in the frequency range from $1 \mathrm{~Hz}$ to $1 \mathrm{MHz}$ with an open-circuit voltage and an AC amplitude of $10 \mathrm{mV}$.
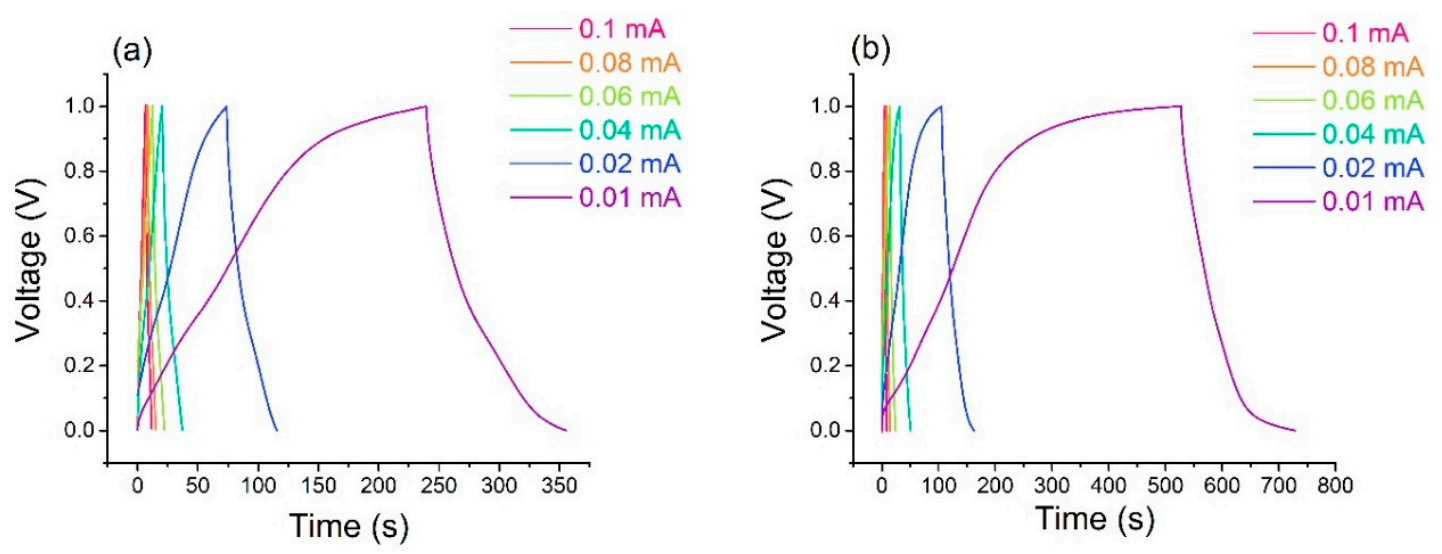

Figure 11. Cont. 


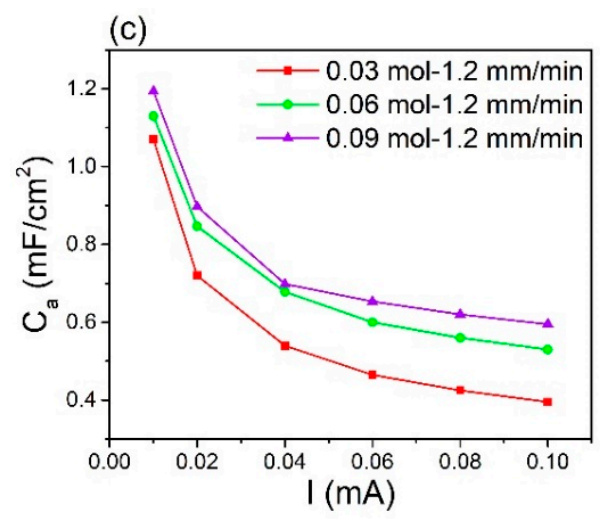

Figure 11. Galvanostatic Charge-discharge curves of (a) 0.06 and (b) $0.09 \mathrm{~mol}$ of $\mathrm{H}_{3} \mathrm{PO}_{4}$ gel electrolyte with a $1.2 \mathrm{~mm} / \mathrm{min}$ scan speed electrode; (c) The calculated areal capacitance for 0.06 and $0.09 \mathrm{~mol}$ of $\mathrm{H}_{3} \mathrm{PO}_{4}$ gel electrolyte with a $1.2 \mathrm{~mm} / \mathrm{min}$ scan speed electrode.

As shown in Figure 12a, the fabricated supercapacitors from the three electrodes deposited with different scan speed $(0.4,0.8$ and $1.2 \mathrm{~mm} / \mathrm{min})$ and $0.03 \mathrm{~mol} \mathrm{H}_{3} \mathrm{PO}_{4}-\mathrm{PVA}$ all exhibited typical AC impedance characteristics of supercapacitors [82]. In the high-frequency region (Figure 12a enlarge view), the intercept with a real impedance ( $\left.Z^{\prime}\right)$ represents an equivalent series resistance $\left(R_{\mathrm{S}}\right)$, which includes the resistance of electrode materials, ionic resistance of electrolyte, and contact resistance between the electrode and current collector; the radius of semicircle is indicative of the electrode conductivity and the charge-transfer resistance $\left(R_{\mathrm{ct}}\right)$ of electrode materials. $R_{S}$ is estimated to be around $1.1 \Omega$ for a $0.4 \mathrm{~mm} / \mathrm{min}$ scan speed electrode, which was larger than that given by a $0.8 \mathrm{~mm} / \mathrm{min}$ electrode scan speed $(0.97 \Omega)$ and $1.2 \mathrm{~mm} / \mathrm{min}$ scan speed electrode $(0.85 \Omega)$. The semicircle diameter represents the value of $R_{\mathrm{ct}}$ obtained for the three electrodes and has a small diameter. This may be due to the formation of graphene-graphite structures on the surface of the $0.4 \mathrm{~mm} / \mathrm{min}$ scan speed electrode; the amount of this formation may have decreased when the scan speed is increased to 0.8 and $1.2 \mathrm{~mm} / \mathrm{min}$, thus improving the impedance of the electrodes. In the intermediate frequency region, the slope of the $45^{\circ}$ portion of the curves is the Warburg resistance, which represents the ion diffusion/transport in the electrolyte. In the low-frequency region, the capacitive behavior of the $1.2 \mathrm{~mm} / \mathrm{min}$ scan speed electrode is evident in the curve. The curve is slightly bent but overall exhibits a good capacitive performance.
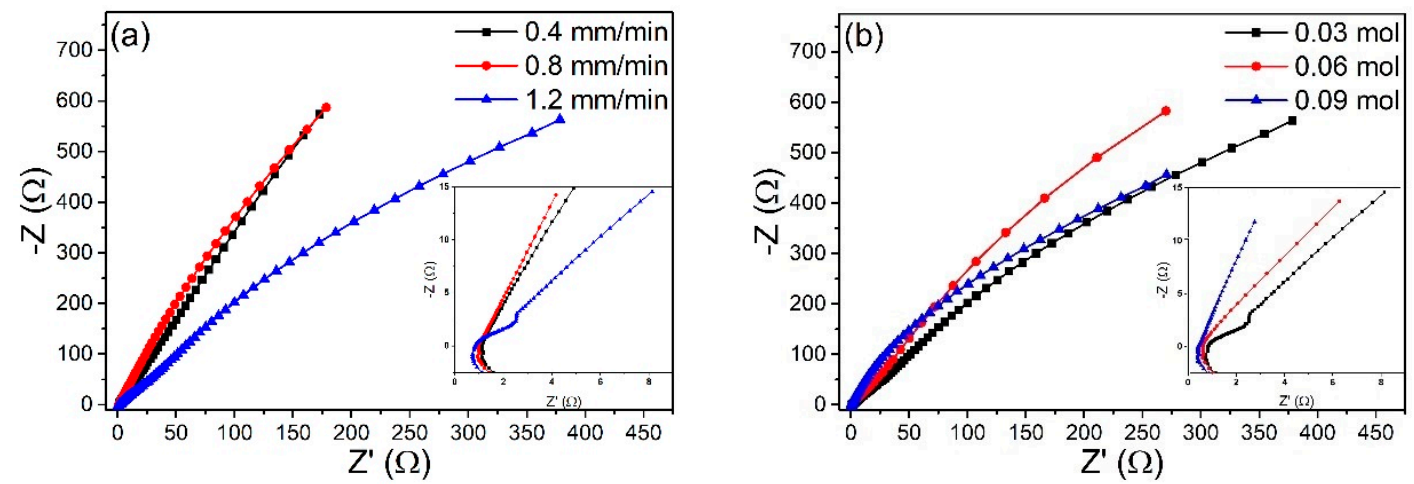

Figure 12. Nyquist plots of (a) 0.03 mol of $\mathrm{H}_{3} \mathrm{PO}_{4}$ gel electrolyte with different scan speeds and (b) $0.03,0.06$ and $0.09 \mathrm{~mol}$ of $\mathrm{H}_{3} \mathrm{PO}_{4}$ gel electrolyte with a $1.2 \mathrm{~mm} / \mathrm{min}$ scan speed electrode.

Nyquist plots of the three typical $1.2 \mathrm{~mm} / \mathrm{min}$ scan speed electrodes with $0.03,0.06$ and $0.09 \mathrm{~mol}$ $\mathrm{H}_{3} \mathrm{PO}_{4}-\mathrm{PVA}$ electrolytes were measured, as shown in Figure $12 \mathrm{~b} . R_{\mathrm{s}}$ values were $0.85,0.62$, and $0.42 \Omega$ respectively, the supercapacitor fabricated with $0.09 \mathrm{~mol} \mathrm{H}_{3} \mathrm{PO}_{4}-\mathrm{PVA}$ electrolyte exhibits a lower 
internal resistance and a smaller semicircular diameter at high frequencies, indicating a better interface between the electrolyte and electrode. The conductivity is dependent on the concentration of the $\mathrm{H}_{3} \mathrm{PO}_{4}$ in the gel electrolyte; as the $\mathrm{H}_{3} \mathrm{PO}_{4}$ concentration increases, the conductivity also increases, meaning the value of $R_{\mathrm{S}}$ decreases as the concentration increases. As a result of increasing the conductivity, mobility of the $\mathrm{H}_{3} \mathrm{PO}_{4}$ is increased; this can consequently decrease the value of $R_{\mathrm{ct}}$, which is represented by the radius of semicircle. This result agrees with previous reports $[48,83]$.

The cyclic stability of the deposited film with a $1.2 \mathrm{~mm} / \mathrm{min}$ scan speed and $0.09 \mathrm{~mol}$ of $\mathrm{H}_{3} \mathrm{PO}_{4}-\mathrm{PVA}$ was investigated at current $0.06 \mathrm{~mA}$, repeating the galvanostatic charge/discharge measurement ranging from 0 to $1 \mathrm{~V}$. As shown in Figure 13, the supercapacitor has a coulombic efficiency of $98 \%$ at the beginning, which decreased to $95 \%$ after 5000 cycles. The good cycling performance of the electrode material indicated a good stability and strong adherence to the stainless-steel substrate. The good cycling stability can be attributed to two reasons. The first reason is that the few-layer graphene nanoflake structure is randomly oriented on the substrate, which allows the electrolyte ions to diffuse through the graphene layers, leading to a good improvement in the electrochemical performance of the supercapacitor. The second reason is the mechanical stability caused by the strong adherence of the few-layer graphene nanoflake structures on the stainless-steel substrate. The degradation in the coulombic efficiency after 5000 cycles is likely due to the consumption of the electrolyte as a result of irreversible reactions between the graphene electrode and the $\mathrm{H}_{3} \mathrm{PO}_{4}-\mathrm{PVA}$ gel electrolyte.

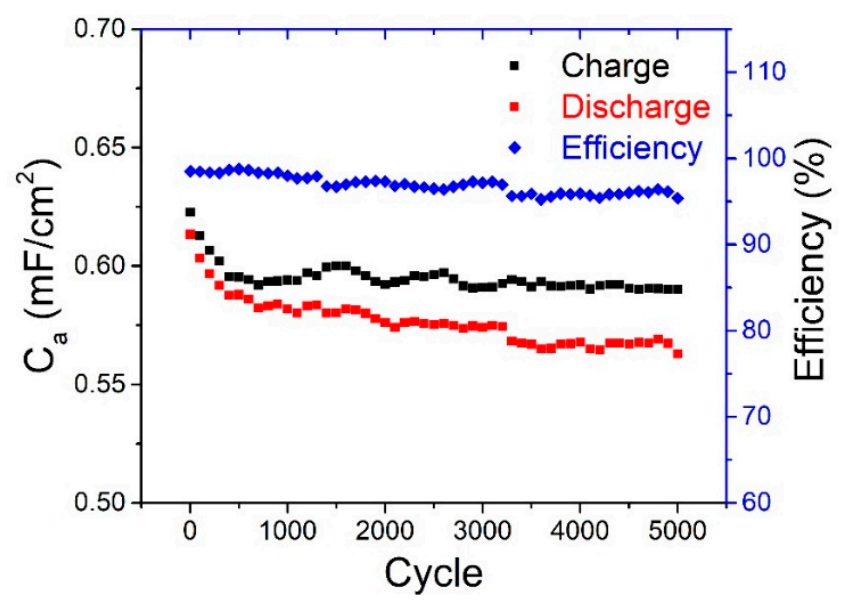

Figure 13. Charge-discharge stability over 5000 cycles for a $1.2 \mathrm{~mm} / \mathrm{min}$ scan speed and $0.09 \mathrm{~mol}$ of $\mathrm{H}_{3} \mathrm{PO}_{4}-\mathrm{PVA}$ at a current of $0.06 \mathrm{~mA}$.

\section{Conclusions}

In this research, a vacuum kinetic spray was used to deposit micro-sized graphite powder on stainless steel substrate at room temperature and low-pressure conditions. The NPDS results in the formation of randomly oriented few-layer graphene nano-flakes; as confirmed by FE-SEM, HR-TEM, $\mathrm{XRD}$, and Raman spectroscopy. Some of the graphite particles fragmented to graphene nano-flakes and some particles did not fragment and were converted to graphite particles with a smaller size than the particles in the original graphite powder. The amount of graphite structure on the deposited films decreases with an increase in the deposition scan speed.

The electrochemical capacitive behavior of the supercapacitors assembled from the deposited films using NPDS, with 0.03 mol PVA- $\mathrm{H}_{3} \mathrm{PO}_{4}$, showed an areal capacitance comparable to other research, and it was improved by increasing the scan speed of the deposition. Also, increasing the amount of $\mathrm{H}_{3} \mathrm{PO}_{4}$ in the PVA gel electrolyte can improve the areal capacitance. The very affordably fabricated supercapacitor with $0.09 \mathrm{~mol} \mathrm{H}_{3} \mathrm{PO}_{4}$-PVA gel electrolyte, produced with a $1.2 \mathrm{~mm} / \mathrm{min}$ deposition scan speed, showed a good stability over 5000 cycles. 
Author Contributions: Conceptualization, D.-M.C. and M.M.M.M.; Methodology, M.M.M.M.; Formal Analysis, M.M.M.M.; Investigation, M.M.M.M.; Resources, D.-M.C.; Data Curation, M.M.M.M.; Writing-Original Draft Preparation, M.M.M.M.; Writing-Review \& Editing, D.-M.C. and M.M.M.M.; Visualization, M.M.M.M.; Supervision, D.-M.C.; Project Administration, D.-M.C.; Funding Acquisition, D.-M.C.

Funding: This research was supported by a National Research Foundation of Korea (NRF) (NRF-2018R1A2B6004012), Nano-Convergence Foundation (www.nanotech2020.org), and the Ministry of Science and ICT (MSIT, Korea) \& Ministry of Trade, Industry and Energy (MOTIE, Korea) (Project name: Establishment of Battery/Ess-Based Energy Industry Innovation Ecosystem).

Conflicts of Interest: The authors declare no conflicts of interest.

\section{References}

1. Miller, J.R.; Simon, P. Electrochemical capacitors for energy management. Science 2008, 321, 651-652. [CrossRef] [PubMed]

2. Simon, P.; Gogotsi, Y. Materials for electrochemical capacitors. Nat. Mater. 2008, 7, 845-854. [CrossRef] [PubMed]

3. Liu, C.; Li, F.; Ma, L.-P.; Cheng, H.-M. Advanced materials for energy storage. Adv. Mater. 2010, 22 , E28-E62. [CrossRef] [PubMed]

4. Kötz, R.; Carlen, M. Principles and applications of electrochemical capacitors. Electrochim. Acta 2000, 45, $2483-2498$. [CrossRef]

5. Kaempgen, M.; Chan, C.K.; Ma, J.; Cui, Y.; Gruner, G. Printable thin film supercapacitors using single-walled carbon nanotubes. Nano Lett. 2009, 9, 1872-1876. [CrossRef] [PubMed]

6. Shakir, I. High energy density based flexible electrochemical supercapacitors from layer-by-layer assembled multiwall carbon nanotubes and graphene. Electrochim. Acta 2014, 129, 396-400. [CrossRef]

7. Geim, A.K.; Novoselov, K.S. The rise of graphene. Nat. Mater. 2007, 6, 183-191. [CrossRef] [PubMed]

8. Geim, A.K. Graphene: Status and prospects. Science 2009, 324, 1530-1534. [CrossRef] [PubMed]

9. Novoselov, K.S.; Geim, A.K.; Morozov, S.V.; Jiang, D.; Katsnelson, M.I.; Grigorieva, I.V.; Dubonos, S.V.; Firsov, A.A. Two-dimensional gas of massless Dirac fermions in graphene. Nature 2005, 438, 197-200. [CrossRef] [PubMed]

10. Peigney, A.; Laurent, C.; Flahaut, E.; Bacsa, R.R.; Rousset, A. Specific surface area of carbon nanotubes and bundles of carbon nanotubes. Carbon 2001, 39, 507-514. [CrossRef]

11. El-Kady, M.F.; Strong, V.; Dubin, S.; Kaner, R.B. Laser scribing of high-performance and flexible graphene-based electrochemical capacitors. Science 2012, 335, 1326-1330. [CrossRef] [PubMed]

12. Abdelkader, A.M.; Karim, N.; Vallés, C.; Afroj, S.; Novoselov, K.S.; Yeates, S.G. Ultraflexible and robust graphene supercapacitors printed on textiles for wearable electronics applications. 2D Mater. 2017, 4, 035016. [CrossRef]

13. Abdelkader, A.M.; Fray, D.J. Controlled electrochemical doping of graphene-based 3D nanoarchitecture electrodes for supercapacitors and capacitive deionisation. Nanoscale 2017, 9, 14548-14557. [CrossRef] [PubMed]

14. Wu, Q.; Xu, Y.; Yao, Z.; Liu, A.; Shi, G. Supercapacitors based on flexible graphene/polyaniline nanofiber composite films. ACS Nano 2010, 4, 1963-1970. [CrossRef] [PubMed]

15. Zhu, Y.; Murali, S.; Stoller, M.D.; Ganesh, K.; Cai, W.; Ferreira, P.j.; Pirkle, A.; Wallace, R.; Cychosz, K.A.; Thommes, M.; et al. Carbon-based supercapacitors produced by activation of graphene. Science 2011, 332, 1537-1541. [CrossRef] [PubMed]

16. Wei, J.; Zang, Z.; Zhang, Y.; Wang, M.; Du, J.; Tang, X. Enhanced performance of light-controlled conductive switching in hybrid cuprous oxide/reduced graphene oxide $\left(\mathrm{Cu}_{2} \mathrm{O} / \mathrm{rGO}\right)$ nanocomposites. Opt. Lett. 2017, 42, 911-914. [CrossRef] [PubMed]

17. Huang, H.; Zhang, J.; Jiang, L.; Zang, Z. Preparation of cubic $\mathrm{Cu}_{2} \mathrm{O}$ nanoparticles wrapped by reduced graphene oxide for the efficient removal of rhodamine B. J. Alloys Compd. 2017, 718, 112-115. [CrossRef]

18. Zang, Z.; Zeng, X.; Wang, M.; Hu, W.; Liu, C.; Tang, X. Tunable photoluminescence of water-soluble AgInZnS-graphene oxide (GO) nanocomposites and their application in-vivo bioimaging. Sens. Actuators B Chem. 2017, 252, 1179-1186. [CrossRef] 
19. Dikin, D.A.; Stankovich, S.; Zimney, E.J.; Piner, R.D.; Dommett, G.H.B.; Evmenenko, G.; Nguyen, S.T.; Ruoff, R.S. Preparation and characterization of graphene oxide paper. Nature 2007, 448, 457-460. [CrossRef] [PubMed]

20. Segal, M. Selling graphene by the ton. Nat. Nanotechnol. 2009, 4, 612-614. [CrossRef] [PubMed]

21. Wu, Z.-S.; Wang, D.-W.; Ren, W.; Zhao, J.; Zhou, G.; Li, F.; Cheng, H.-M. Anchoring hydrous $\mathrm{RuO}_{2}$ on Graphene sheets for high-performance electrochemical capacitors. Adv. Funct. Mater. 2010, 20, 3595-3602. [CrossRef]

22. Novoselov, K.S.; Geim, A.K.; Morozov, S.V.; Jiang, D.; Zhang, Y.; Dubonos, S.V.; Grigorieva, I.V.; Firsov, A.A. Electric Field effect in atomically thin carbon films. Science 2004, 306, 666-669. [CrossRef] [PubMed]

23. Singh, V.; Joung, D.; Zhai, L.; Das, S.; Khondaker, S.I.; Seal, S. Graphene based materials: Past, present and future. Prog. Mater. Sci. 2011, 56, 1178-1271. [CrossRef]

24. Park, S.; Ruoff, R.S. Chemical methods for the production of graphenes. Nat. Nanotechnol. 2009, 4, $217-224$. [CrossRef] [PubMed]

25. Ambrosi, A.; Pumera, M. Electrochemically exfoliated graphene and graphene oxide for energy storage and electrochemistry applications. Chem. A Eur. J. 2016, 22, 153-159. [CrossRef] [PubMed]

26. Chen, C.-H.; Yang, S.-W.; Chuang, M.-C.; Woon, W.-Y.; Su, C.-Y. Towards the continuous production of high crystallinity graphene via electrochemical exfoliation with molecular in situ encapsulation. Nanoscale 2015, 7, 15362-15373. [CrossRef] [PubMed]

27. Abdelkader, A.M.; Cooper, A.J.; Dryfe, R.A.W.; Kinloch, I.A. How to get between the sheets: A review of recent works on the electrochemical exfoliation of graphene materials from bulk graphite. Nanoscale 2015, 7, 6944-6956. [CrossRef] [PubMed]

28. Ossonon, B.D.; Bélanger, D. Functionalization of graphene sheets by the diazonium chemistry during electrochemical exfoliation of graphite. Carbon 2017, 111, 83-93. [CrossRef]

29. Yang, S.; Brüller, S.; Wu, Z.-S.; Liu, Z.; Parvez, K.; Dong, R.; Richard, F.; Samorì, P.; Feng, X.; Müllen, K. Organic Radical-assisted electrochemical exfoliation for the scalable production of high-quality graphene. J. Am. Chem. Soc. 2015, 137, 13927-13932. [CrossRef] [PubMed]

30. Hernandez, Y.; Nicolosi, V.; Lotya, M.; Blighe, F.M.; Sun, Z.; De, S.; McGovern, I.T.; Holland, B.; Byrne, M.; Gun'Ko, Y.K.; et al. High-yield production of graphene by liquid-phase exfoliation of graphite. Nat. Nanotechnol. 2008, 3, 563-568. [CrossRef] [PubMed]

31. Behabtu, N.; Lomeda, J.R.; Green, M.J.; Higginbotham, A.L.; Sinitskii, A.; Kosynkin, D.V.; Tsentalovich, D.; Parra-Vasquez, A.N.G.; Schmidt, J.; Kesselman, E.; et al. Spontaneous high-concentration dispersions and liquid crystals of graphene. Nat. Nanotechnol. 2010, 5, 406-411. [CrossRef] [PubMed]

32. Sun, Y.; Wu, Q.; Shi, G. Graphene based new energy materials. Energy Environ. Sci. 2011, 4, 1113-1132. [CrossRef]

33. Ferrari, A.C.; Bonaccorso, F.; Fal'ko, V.; Novoselov, K.S.; Roche, S.; Boggild, P.; Borini, S.; Koppens, F.H.L.; Palermo, V.; Pugno, N.; et al. Science and technology roadmap for graphene, related two-dimensional crystals, and hybrid systems. Nanoscale 2015, 7, 4598-4810. [CrossRef] [PubMed]

34. Reina, A.; Jia, X.; Ho, J.; Nezich, D.; Son, H.; Bulovic, V.; Dresselhaus, M.S.; Kong, J. Large area, few-layer graphene films on arbitrary substrates by chemical vapor deposition. Nano Lett. 2009, 9, 30-35. [CrossRef] [PubMed]

35. Bae, S.; Kim, H.; Lee, Y.; Xu, X.; Park, J.-S.; Zheng, Y.; Balakrishnan, J.; Lei, T.; Kim, H.R.; Song, Y.I.; et al. Roll-to-roll production of 30-inch graphene films for transparent electrodes. Nat. Nanotechnol. 2010, 5, 574-578. [CrossRef] [PubMed]

36. Cai, W.; Moore, A.L.; Zhu, Y.; Li, X.; Chen, S.; Shi, L.; Ruoff, R.S. Thermal transport in suspended and supported monolayer graphene grown by chemical vapor deposition. Nano Lett. 2010, 10, 1645-1651. [CrossRef] [PubMed]

37. Cai, W.; Piner, R.D.; Zhu, Y.; Li, X.; Tan, Z.; Floresca, H.C.; Yang, C.; Lu, L.; Kim, M.J.; Ruoff, R.S. Synthesis of isotopically-labeled graphite films by cold-wall chemical vapor deposition and electronic properties of graphene obtained from such films. Nano Res. 2009, 2, 851. [CrossRef]

38. Fallahazad, B.; Hao, Y.; Lee, K.; Kim, S.; Ruoff, R.S.; Tutuc, E. Quantum hall effect in Bernal stacked and twisted bilayer graphene grown on $\mathrm{Cu}$ by chemical vapor deposition. Phys. Rev. B 2012, 85, 201408. [CrossRef] 
39. Li, X.; Magnuson, C.W.; Venugopal, A.; Tromp, R.M.; Hannon, J.B.; Vogel, E.M.; Colombo, L.; Ruoff, R.S. Large-area graphene single crystals grown by low-pressure chemical vapor deposition of methane on copper. J. Am. Chem. Soc. 2011, 133, 2816-2819. [CrossRef] [PubMed]

40. Suk, J.W.; Kitt, A.; Magnuson, C.W.; Hao, Y.; Ahmed, S.; An, J.; Swan, A.K.; Goldberg, B.B.; Ruoff, R.S. Transfer of CVD-grown monolayer graphene onto arbitrary substrates. ACS Nano 2011, 5, 6916-6924. [CrossRef] [PubMed]

41. Allen, M.J.; Tung, V.C.; Kaner, R.B. Honeycomb carbon: A review of graphene. Chem. Rev. 2010, 110, $132-145$. [CrossRef] [PubMed]

42. Chun, D.M.; Kim, M.H.; Lee, J.C.; Ahn, S.H. TiO 2 coating on metal and polymer substrates by nano-particle deposition system (NPDS). CIRP Ann. Manuf. Technol. 2008, 57, 551-554. [CrossRef]

43. Chun, D.-M.; Kim, M.-H.; Lee, J.-C.; Ahn, S.-H. A nano-particle deposition system for ceramic and metal coating at room temperature and low vacuum conditions. Int. J. Precis. Eng. Manuf. 2008, 9, 51-53.

44. Jung, K.; Song, W.; Chun, D.-M.; Kim, Y.-H.; Yeo, J.-C.; Kim, M.-S.; Ahn, S.-H.; Lee, C.-S. Nickel line patterning using silicon supersonic micronozzle integrated with a nanoparticle deposition system. Jpn. J. Appl. Phys. 2010, 49, 05EC09. [CrossRef]

45. Sheng, K.; Sun, Y.; Li, C.; Yuan, W.; Shi, G. Ultrahigh-rate supercapacitors based on eletrochemically reduced graphene oxide for ac line-filtering. Sci. Rep. 2012, 2, 247. [CrossRef] [PubMed]

46. Nasim, M.N.E.A.A.; Chun, D.-M. Formation of few-layer graphene flake structures from graphite particles during thin film coating using dry spray deposition method. Thin Solid Films 2017, 622, 34-40. [CrossRef]

47. Nasim, M.N.E.A.A.; Chun, D.-M. Substrate-dependent deposition behavior of graphite particles dry-sprayed at room temperature using a nano-particle deposition system. Surf. Coat. Technol. 2017, 309, 172-178. [CrossRef]

48. Chen, Q.; Li, X.; Zang, X.; Cao, Y.; He, Y.; Li, P.; Wang, K.; Wei, J.; Wu, D.; Zhu, H. Effect of different gel electrolytes on graphene-based solid-state supercapacitors. RSC Adv. 2014, 4, 36253-36256. [CrossRef]

49. Li, S.; Wang, X.; Xing, H.; Shen, C. Micro supercapacitors based on a 3D structure with symmetric graphene or activated carbon electrodes. J. Micromech. Microeng. 2013, 23, 114013. [CrossRef]

50. Yu, K.; Zhao, W.; Wu, X.; Zhuang, J.; Hu, X.; Zhang, Q.; Sun, J.; Xu, T.; Chai, Y.; Ding, F.; et al. In situ atomic-scale observation of monolayer graphene growth from SiC. Nano Res. 2018, 11, 2809-2820. [CrossRef]

51. Muthurasu, A.; Dhandapani, P.; Ganesh, V. Facile and simultaneous synthesis of graphene quantum dots and reduced graphene oxide for bio-imaging and supercapacitor applications. New J. Chem. 2016, 40, 9111-9124. [CrossRef]

52. Kumar, G.S.; Thupakula, U.; Sarkar, P.K.; Acharya, S. Easy extraction of water-soluble graphene quantum dots for light emitting diodes. RSC Adv. 2015, 5, 27711-27716. [CrossRef]

53. Robertson, A.W.; Warner, J.H. Atomic resolution imaging of graphene by transmission electron microscopy. Nanoscale 2013, 5, 4079-4093. [CrossRef] [PubMed]

54. Tuinstra, F.; Koenig, J.L. Raman spectrum of graphite. J. Chem. Phys. 1970, 53, 1126-1130. [CrossRef]

55. Ferrari, A.C. Raman spectroscopy of graphene and graphite: Disorder, electron-phonon coupling, doping and nonadiabatic effects. Solid State Commun. 2007, 143, 47-57. [CrossRef]

56. Cançado, L.G.; Pimenta, M.A.; Neves, B.R.A.; Medeiros-Ribeiro, G.; Enoki, T.; Kobayashi, Y.; Takai, K.; Fukui, K.; Dresselhaus, M.S.; Saito, R.; et al. Anisotropy of the Raman spectra of nanographite ribbons. Phys. Rev. Lett. 2004, 93, 047403. [CrossRef] [PubMed]

57. Nemanich, R.J.; Solin, S.A. First- and second-order Raman scattering from finite-size crystals of graphite. Phys. Rev. B 1979, 20, 392-401. [CrossRef]

58. Vidano, R.P.; Fischbach, D.B.; Willis, L.J.; Loehr, T.M. Observation of Raman band shifting with excitation wavelength for carbons and graphites. Solid State Commun. 1981, 39, 341-344. [CrossRef]

59. Pócsik, I.; Hundhausen, M.; Koós, M.; Ley, L. Origin of the D peak in the Raman spectrum of microcrystalline graphite. J. Non Cryst. Solids 1998, 227, 1083-1086. [CrossRef]

60. Maultzsch, J.; Reich, S.; Thomsen, C.; Requardt, H.; Ordejón, P. Phonon dispersion in graphite. Phys. Rev. Lett. 2004, 92, 075501. [CrossRef] [PubMed]

61. Wang, H.; Wang, Y.; Cao, X.; Feng, M.; Lan, G. Vibrational properties of graphene and graphene layers. J. Raman Spectrosc. 2009, 40, 1791-1796. [CrossRef] 
62. Hiramatsu, M.; Shiji, K.; Amano, H.; Hori, M. Fabrication of vertically aligned carbon nanowalls using capacitively coupled plasma-enhanced chemical vapor deposition assisted by hydrogen radical injection. Appl. Phys. Lett. 2004, 84, 4708-4710. [CrossRef]

63. Hiramatsu, M.; Hori, M. Fabrication of carbon nanowalls using novel plasma processing. Jpn. J. Appl. Phys. 2006, 45, 5522. [CrossRef]

64. Mori, T.; Hiramatsu, M.; Yamakawa, K.; Takeda, K.; Hori, M. Fabrication of carbon nanowalls using electron beam excited plasma-enhanced chemical vapor deposition. Diam. Relat. Mater. 2008, 17, 1513-1517. [CrossRef]

65. Ni, Z.; Wang, Y.; Yu, T.; Shen, Z. Raman spectroscopy and imaging of graphene. Nano Res. 2008, 1, $273-291$. [CrossRef]

66. Wang, M.; Liu, Q.; Sun, H.; Stach, E.A.; Zhang, H.; Stanciu, L.; Xie, J. Preparation of high-surface-area carbon nanoparticle/graphene composites. Carbon 2012, 50, 3845-3853. [CrossRef]

67. Liu, J.; Notarianni, M.; Will, G.; Tiong, V.T.; Wang, H.; Motta, N. Electrochemically exfoliated graphene for electrode films: effect of graphene flake thickness on the sheet resistance and capacitive properties. Langmuir 2013, 29, 13307-13314. [CrossRef] [PubMed]

68. Galindo, B.; Alcolea, S.G.; Gómez, J.; Navas, A.; Murguialday, A.O.; Fernandez, M.P.; Puelles, R.C. Effect of the number of layers of graphene on the electrical properties of TPU polymers. IOP Conf. Ser. Mater. Sci. Eng. 2014, 64, 012008. [CrossRef]

69. Srinivasan, V.; Weidner, J.W. Studies on the capacitance of nickel oxide films: effect of heating temperature and electrolyte concentration. J. Electrochem. Soc. 2000, 147, 880-885. [CrossRef]

70. Zheng, J.P.; Jow, T.R. The effect of salt concentration in electrolytes on the maximum energy storage for double layer capacitors. J. Electrochem. Soc. 1997, 144, 2417-2420. [CrossRef]

71. Torchała, K.; Kierzek, K.; Machnikowski, J. Capacitance behavior of KOH activated mesocarbon microbeads in different aqueous electrolytes. Electrochim. Acta 2012, 86, 260-267. [CrossRef]

72. Yu, X.; Kim, H.J.; Hong, J.-Y.; Jung, Y.M.; Kwon, K.D.; Kong, J.; Park, H.S. Elucidating surface redox charge storage of phosphorus-incorporated graphenes with hierarchical architectures. Nano Energy 2015, 15, 576-586. [CrossRef]

73. Wen, Y.; Wang, B.; Huang, C.; Wang, L.; Hulicova-Jurcakova, D. Synthesis of phosphorus-doped graphene and its wide potential window in aqueous supercapacitors. Chem. A Eur. J. 2014, 21, 80-85. [CrossRef] [PubMed]

74. Thirumal, V.; Pandurangan, A.; Jayavel, R.; Venkatesh, K.S.; Palani, N.S.; Ragavan, R.; Ilangovan, R. Single pot electrochemical synthesis of functionalized and phosphorus doped graphene nanosheets for supercapacitor applications. J. Mater. Sci. Mater. Electron. 2015, 26, 6319-6328. [CrossRef]

75. Pan, H.; Poh, C.K.; Feng, Y.P.; Lin, J. Supercapacitor electrodes from tubes-in-tube carbon nanostructures. Chem. Mater. 2007, 19, 6120-6125. [CrossRef]

76. Xie, B.; Chen, Y.; Yu, M.; Zhang, S.; Lu, L.; Shu, Z.; Zhang, Y. Phosphoric acid-assisted synthesis of layered $\mathrm{MoS}_{2}$ /graphene hybrids with electrolyte-dependent supercapacitive behaviors. RSC Adv. 2016, 6, 89397-89406. [CrossRef]

77. Li, X.; Zhao, T.; Chen, Q.; Li, P.; Wang, K.; Zhong, M.; Wei, J.; Wu, D.; Wei, B.; Zhu, H. Flexible all solid-state supercapacitors based on chemical vapor deposition derived graphene fibers. Phys. Chem. Chem. Phys. 2013, 15, 17752-17757. [CrossRef] [PubMed]

78. Yoo, J.J.; Balakrishnan, K.; Huang, J.; Meunier, V.; Sumpter, B.G.; Srivastava, A.; Conway, M.; Mohana Reddy, A.L.; Yu, J.; Vajtai, R.; et al. Ultrathin planar graphene supercapacitors. Nano Lett. 2011, 11, 1423-1427. [CrossRef] [PubMed]

79. Miller, J.R.; Outlaw, R.A.; Holloway, B.C. Graphene double-layer capacitor with ac line-filtering performance. Science 2010, 329, 1637-1639. [CrossRef] [PubMed]

80. Lin, J.; Zhang, C.; Yan, Z.; Zhu, Y.; Peng, Z.; Hauge, R.H.; Natelson, D.; Tour, J.M. 3-Dimensional graphene carbon nanotube carpet-based microsupercapacitors with high electrochemical performance. Nano Lett. 2013, 13, 72-78. [CrossRef] [PubMed]

81. Wu, Z.S.; Liu, Z.; Parvez, K.; Feng, X.; Müllen, K. Ultrathin printable graphene supercapacitors with AC line-filtering performance. Adv. Mater. 2015, 27, 3669-3675. [CrossRef] [PubMed] 
82. Qu, D. Studies of the activated carbons used in double-layer supercapacitors. J. Power Sources 2002, 109, $403-411$. [CrossRef]

83. Khiar, A.S.A.; Arof, A.K. Conductivity studies of starch-based polymer electrolytes. Ionics 2010, 16, 123-129. [CrossRef] 